Nereis. Revista Iberoamericana Interdisciplinar de Métodos, Modelización y Simulación

\title{
Inhibición de motilidad y Quorum sensing bacteriano por desechos de vinificación
}

\author{
Inhibition of motility and Quorum sensing bacteria due to winemaking waste
}

Fecha de recepción y aceptación: 22 de febrero de 2020, 24 de abril de 2020

DOI: $10.46583 /$ nereis_2020.12.580

\author{
Carolina María Viola ${ }^{1}$, María Rosa Alberto ${ }^{1,2}$, Elena Cartagena ${ }^{1,2}$ y Mario Eduardo Arena ${ }^{1,2^{*}}$ \\ ${ }^{1}$ Instituto de Biotecnología Farmacéutica y alimentaria (INBIOFAL). CONICET- Universidad Nacional de Tucumán. \\ ${ }^{2}$ Facultad de Bioquímica, Química y Farmacia. Universidad Nacional de Tucumán. \\ * Correspondencia: Universidad Nacional de Tucumán. Facultad de Bioquímica, Química y Farmacia. Batalla de Ayacucho 471 - CPA \\ T4000INI. San Miguel de Tucumán. Tucumán. Argentina.E-mail: arename@fbqf.unt.edu.ar
}

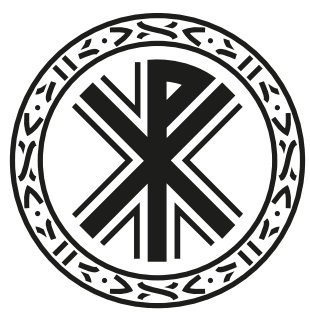

\section{RESUMEN}

En la industria de alimentos, el biofilm es la principal causa de contaminación. Debido a normativas alimentarias, solo pocos compuestos pueden ser usados como conservantes o estar en contacto con alimentos durante su elaboración y a la vez deben ser económicos. Una alternativa es el uso de subproductos o residuos de agroindustrias. Una de las principales industrias alimenticias de Iberoamérica es la vitivinicultura. La presente investigación utiliza orujo y escobajo de vino varietal Torrontés para inhibir la virulencia bacteriana controlada por Quorum sensing (QS) y principalmente su motilidad (swarming y swimming), lo que permitiría el desplazamiento y la formación de biofilm en alimentos. Realizamos extracciones con solventes de polaridad creciente (hexano, cloroformo, acetato de etilo y metanol). Enfrentamos 250 y $500 \mu \mathrm{g} / \mathrm{ml} \mathrm{de} \mathrm{extractos}$ (E) a las cepas de Pseudomonas aeruginosa ATCC 27853 y LVP65. Los E metanólicos de orujo y escobajo inhibieron más del 50 la motilidad swarming de ambas cepas. Los E acetato de etilo inhibieron swimming (25-30\%). La actividad anti-QS de los E se ensayó con las cepas Chromobacterium violaceum ATCC 12472 y CV026 y se determinó una inhibición de los E metanólicos y de acetato sobre el sistema de QS. Las bioactividades encontradas convierten a estos desechos en una novedosa alternativa para la preservación de alimentos.

PALABRAS CLAVE: residuos agroindustriales, Quorum sensing, motilidad.

\section{ABSTRACT}

In the food industry, biofilm is the main cause of contamination. Due to food regulations, only a few compounds can be used as preservatives or be in contact with food during their preparation and, at the same time, they must be economical. An alternative is the use of by-products or agro-industry waste. One of the main food industries in Latin America is viticulture. The present research uses marc and stems of Torrontés varietal wine to inhibit the bacterial virulence controlled by Quorum sensing (QS) and its motility (swarming and swimming), which would 
allow the displacement and formation of biofilm in foods. We perform extractions with solvents of increasing polarity (hexane, chloroform, ethyl acetate, and methanol). We compare 250 and $500 \mu \mathrm{g} / \mathrm{ml}$ of extracts to the strains of Pseudomonas aeruginosa ATCC 27853 and LVP65. Methanolic extracts to marc and stems inhibited more than 50 swarming motility of both strains. In addition, both ethyl acetate extracts inhibited the swimming (25-30\%). The anti-QS activity of the Extracts was tested with strains Chromobacterium violaceum ATCC 12472 and CV026 and an inhibition of the methanolic and acetate extracts on the QS system was determined. The bioactivities found make a novel alternative for food preservation out of this waste.

KEYWORDS: agro-industrial waste, Quorum sensing, motility.

\section{INTRODUCCIÓN}

La persistencia y expansión de los patógenos transmitidos por los alimentos y sus enfermedades asociadas constituyen una preocupación primordial de salud pública. La capacidad de los patógenos bacterianos para adaptarse y sobrevivir en entornos estresantes de procesamiento de alimentos y el tracto gastrointestinal del hospedador o anfitrión contribuye a aumentar las enfermedades transmitidas por los alimentos [1]. Ejemplo de ello es el patógeno oportunista Pseudomonas aeruginosa, responsable de infecciones intrahospitalarias y alimenticias debido a su resistencia a los antibióticos y procesos de desinfección. Su patogenicidad se debe a la producción coordinada de factores de virulencia controlados por Quorum sensing (QS), tales como biofilm, enzimas, producción de pigmentos y motilidad.

El QS es un mecanismo de comunicación química dependiente de la densidad poblacional a través del cual las bacterias regulan la expresión de una gran variedad de genes relacionados con el control de diferentes procesos a nivel celular. Este sistema de regulación bacteriano censa la densidad poblacional celular mediante la acumulación de moléculas de señalización química, denominadas autoinductores, que son producidos por las mismas bacterias, acil homoserina lactonas (AHL) [2-4]. Cuando estas moléculas alcanzan una concentración umbral, se desencadenan diversos procesos tales como bioluminiscencia, formación de biopelículas, motilidad y resistencia a antibióticos $[3,5,6]$.

La detección del QS bacteriano está implicada en una serie de procesos bacterianos patológicos, por lo que es un objetivo clave controlar la expresión de genes de virulencia, entre ellos los que producen biopelículas y otros factores de patogenicidad [6,7]. Uno de ellos es la motilidad tipo swarming. Este es un movimiento a través de una superficie semisólida que requiere de flagelos y producción de biosurfactantes [8]. Por otra parte, la motilidad swimming es un movimiento en condiciones semilíquidas y requiere de un flagelo funcional, pero no de sistemas de detección de QS, sin embargo, su eliminación cobra importancia porque la reducción de esta motilidad aumenta la fuerza de repulsión de la cepa con la superficie e inhibe una posible adhesión estable con esta, lo cual afecta el progreso hacia la formación de un biofilm maduro $[9,10]$.

El análisis de productos naturales e identificación de moléculas inhibidoras de QS representa un avance prometedor como terapia alternativa a los antibióticos al no ejercer presión selectiva ni generar problemas de resistencia microbiana [11,12], por lo tanto para contrarrestar dicha problemática se contempla la utilización estratégica de productos naturales derivados de las agroindustrias regionales, 
como puede ser la industria vitivinícola, la cual produce grandes cantidades de residuos ricos en compuestos bioactivos, tales como orujos, borras, escobajos, aguas residuales y residuos inorgánicos [13]. El orujo es el residuo originado en el proceso de prensado y consiste, principalmente, en semillas y piel, mientras que el escobajo es el armazón de sostén de los granos en el racimo y proviene del proceso de despalillado. Actualmente, estos residuos no se valoran como rentables y se destinan, principalmente, al compostaje o se descartan en áreas abiertas, lo que provoca un problema de gestión de residuos, con implicancias importantes desde el punto de vista higiénico, económico y ecológico [14,15].

En este trabajo se propone valorizar los residuos de la industria vitivinícola regional utilizando orujo y escobajo de vino Torrontés como fuente de compuestos bioactivos con potencial anti-QS y capacidad para controlar la motilidad swarming y swimming de cepas de $P$. aeruginosa y al mismo tiempo reducir el impacto ambiental de las actividades de vinificación.

\section{MATERIALES Y MÉTODOS}

\section{Muestras y obtención de extractos}

Las muestras fueron orujo y escobajo de vino blanco de varietal Torrontés cedidas por la Bodega Vasija Secreta de Cafayate en Salta (Argentina). La obtención se llevó a cabo mediante la técnica de extracción sólido-líquido, utilizando solventes de polaridad creciente: hexano, cloroformo, acetato de etilo y metanol. Los extractos obtenidos fueron EHO: extracto hexánico de orujo; ECO: extracto clorofórmico de orujo; EAO: extracto acetato de etilo de orujo; EMO: extracto metanólico de orujo; EHE: extracto hexánico de escobajo; ECE: extracto clorofórmico de escobajo; EAE: extracto acetato de etilo de escobajo; EME: extracto metanólico de escobajo.

\section{Cepas bacterianas}

- Chromobacterium violaceum (12472): produce pigmento violaceína regulado por QS.

- Chromobacterium violaceum (CVO26): cepa biosensora, mutante mini-Tn5 de la cepa de tipo salvaje, deficiente en Cvil sintasa autoinductora [16].

- P. aeruginosa ATCC 27853 es una bacteria patógena que tiene factores de virulencia controlados por QS, aislada de sangre de origen hospitalario y utilizada para examinar la susceptibilidad a los antibióticos, el desarrollo de biopelículas y las actividades metabólicas de Pseudomonas [17]. Pseudomonas aeruginosa multirresitente (LVP65), resistente a aztreonam (30 $\mu \mathrm{g})$, ceftazidima (30 $\mu \mathrm{g})$, cefepime (30 $\mu \mathrm{g})$, ciprofloxacina $(5 \mu \mathrm{g})$, gentamicina $(10 \mu \mathrm{g})$, imipenem (10 $\mu \mathrm{g})$, meropenem $(10 \mu \mathrm{g})$ y piperacilina-tazobactam $(110 \mu \mathrm{g})$, y sensible a amikacina $(30 \mu \mathrm{g})$.

\section{Detección de actividad anti-QS}

Mediante el método de pocillo en agar [16] se prepararon placas de medio LB-tripteína agar y se inoculó en un ensayo la cepa Chromobacterium violaceum ATCC 12472 y otro con una cepa mutante, 
Chromobacterium violaceum CV026. Esta última no produce autoinductor de QS pero responde a la presencia del autoinductor (hexanoil homoserina lactona), lo que produce en forma directamente proporcional los factores de virulencia que, en caso de $C$. violaceum, incluyen el pigmento violaceína.

Se realizó un pocillo central donde se colocaron los respectivos extractos en dosis de 5 y 2,5 mg. Posteriormente las placas se incubaron a $28{ }^{\circ} \mathrm{C}$ durante $24 \mathrm{~h}$. La presencia de un halo claro opaco indica la actividad de detección antiquórum de los extractos y la presencia de un halo transparente es una indicación de inhibición del crecimiento.

\section{Motilidad bacteriana}

Se evaluó el efecto de todos los extractos en la motilidad de Pseudomonas aeruginosa ATCC 27853 y Pseudomonas aeruginosa LVP65 a $500 \mu \mathrm{g} / \mathrm{ml}$ y $250 \mu \mathrm{g} / \mathrm{ml}$ en placas semisólidas (swarming) y semi-líquidas (swimming). Las placas fueron inoculadas y posteriormente incubadas a $37^{\circ} \mathrm{C}$. Los halos de movimiento fueron determinados, fijando como escala el diámetro de la placa de Petri y realizando 8 mediciones de los radios, desde el punto de siembra con el programa Image J $1.47 \mathrm{~V}$ $[8,9,17,18]$.

\section{RESULTADOS}

\section{Efecto de los extractos en la motilidad bacteriana}

\section{Swarming de Pseudomonas aeruginosa ATCC 27853}

La invasión bacteriana es un requisito previo para la formación de biopelículas. Por lo tanto, se estudió el efecto de los extractos sobre la motilidad de cepas de P. aeruginosa.

Los extractos de orujo y escobajo disminuyeron, diferencialmente, el swarming de $P$. aeruginosa ATCC 2753 a las concentraciones ensayadas. Se observó mayor inhibición del halo de movimiento en los extractos de orujo, respecto a los extractos de escobajo. El extracto EMO produjo una inhibición mayor al $65 \%$, tanto a $250 \mu \mathrm{g} / \mathrm{mL}$ como a $500 \mu \mathrm{g} / \mathrm{mL}$, como se muestra en la figura 1 . Los extractos de escobajo solo atenuaron la motilidad swarming en un rango del 49 al 64\%, a la mayor concentración. Mientras que el extracto metanólico, al igual que en orujo, ejerció el mayor efecto inhibitorio $(64 \%)$. 


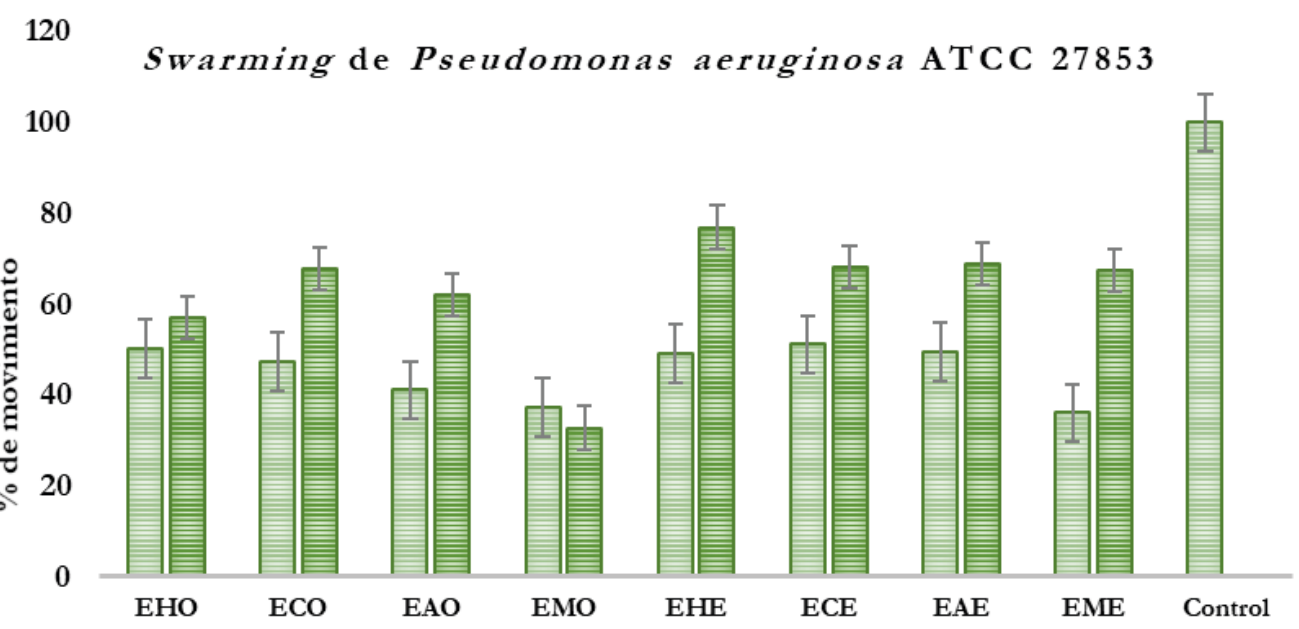

$\square 500 \mu \mathrm{g} / \mathrm{mL} \quad$ 目 $250 \mu \mathrm{g} / \mathrm{mL}$

Fig. 1. Promedio de los radios del halo de movimiento swarming de Pseudomonas aeruginosa ATCC 27853 expresados en porcentaje. EHO: extracto hexánico de orujo; ECO: extracto clorofórmico de orujo; EAO: extracto acetato de etilo de orujo; EMO: extracto metanólico de orujo; EHE: extracto hexánico de escobajo; ECE: extracto clorofórmico de escobajo; EAE: extracto acetato de etilo de escobajo; EME: extracto metanólico de escobajo.
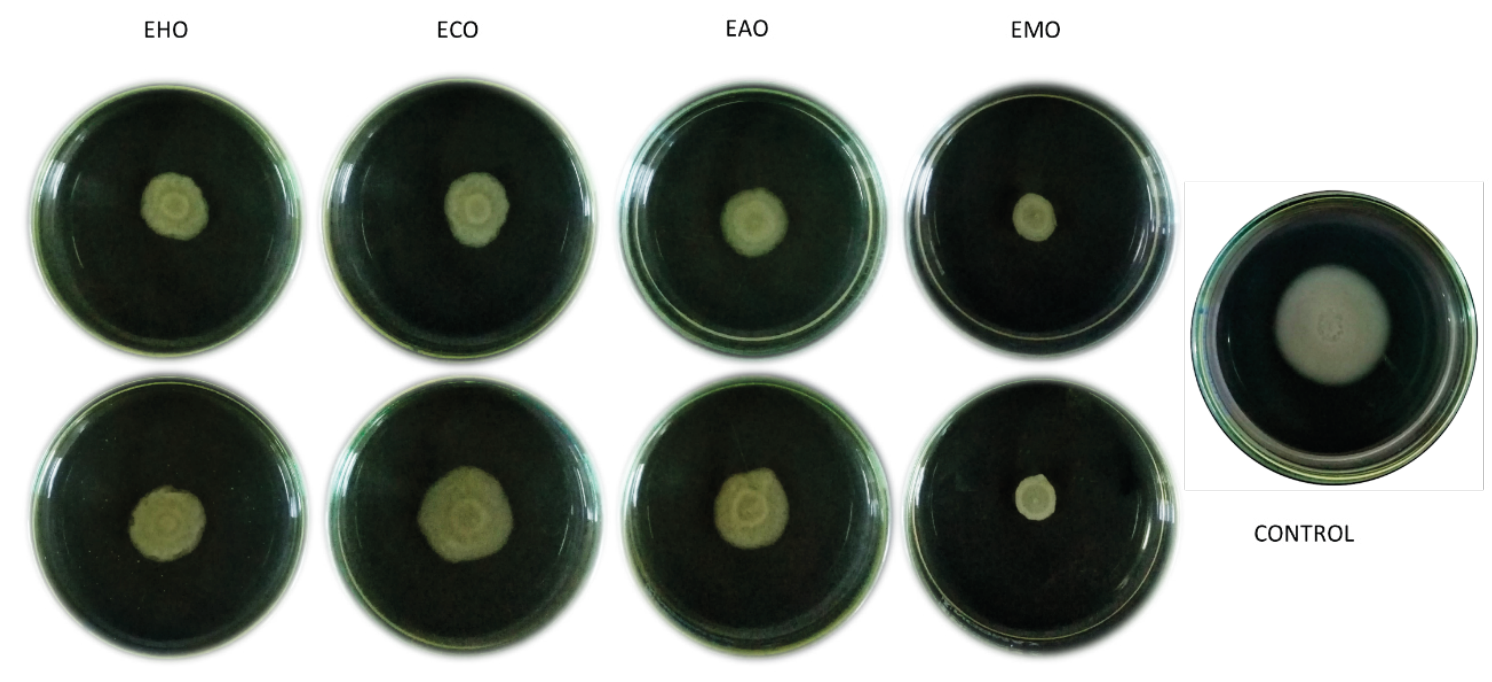

Fig. 2. Motilidad tipo swarming de P. aeruginosa ATCC 27853 en presencia de extractos de orujo de vino Torrontés a $500 \mu \mathrm{g} / \mathrm{mL}$ (fila superior) y a $250 \mu \mathrm{g} / \mathrm{mL}$ (fila inferior). EHO: extracto hexánico de orujo; ECO: extracto clorofórmico de orujo; EAO: extracto acetato de etilo de orujo; EMO: extracto metanólico de orujo. 

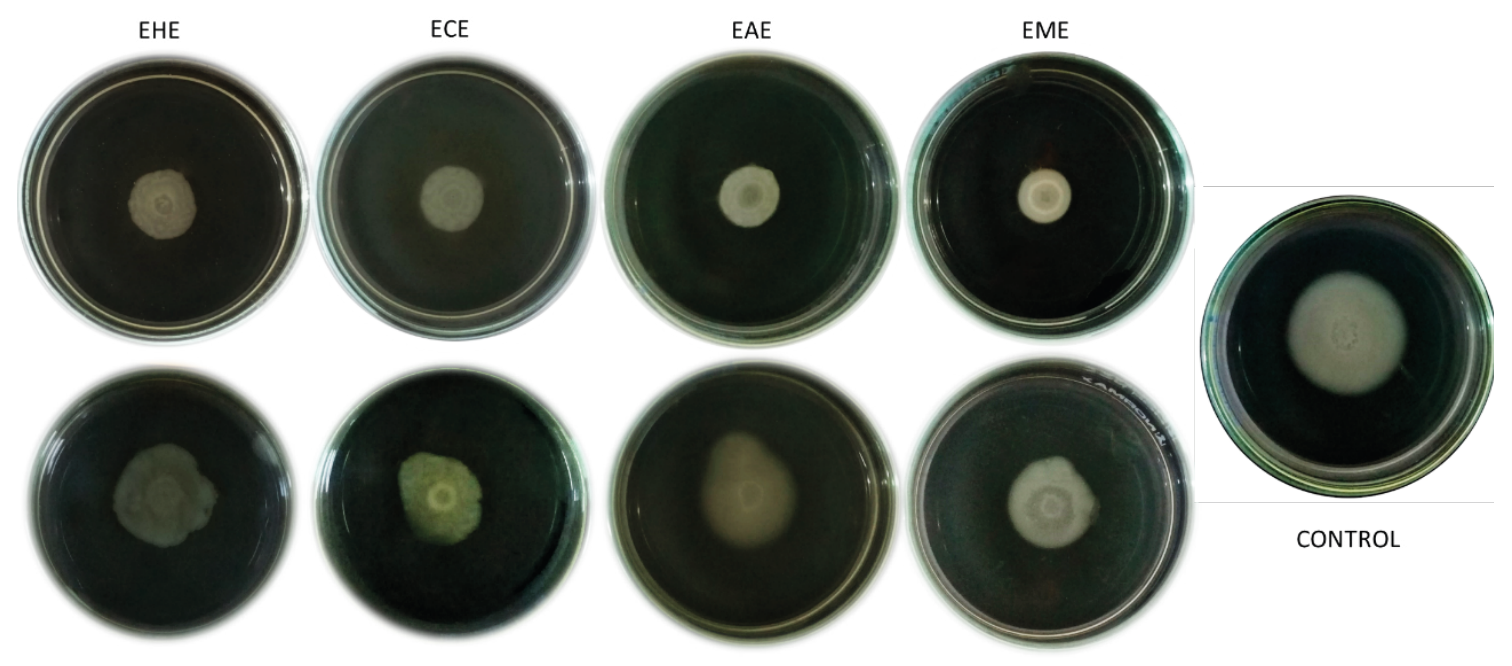

Fig. 3. Motilidad tipo swarming de $P$. aeruginosa ATCC 27853 en presencia de extractos de escobajo de vino Torrontés a $500 \mu \mathrm{g} / \mathrm{mL}$ (fila superior) y a $250 \mu \mathrm{g} / \mathrm{mL}$ (fila inferior). EHE: extracto hexánico de escobajo; ECE: extracto

clorofórmico de escobajo; EAE: extracto acetato de etilo de escobajo; EME: extracto metanólico de escobajo.

\section{Swarming de Pseudomonas aeruginosa LVP65}

La motilidad bacteriana de la cepa resistente a múltiples antibióticos (LVP65) fue afectada por todos los extractos, tanto los procedentes de orujo como los de escobajo. A la concentración de 500 $\mu \mathrm{g} / \mathrm{mL}$, el halo de movimiento fue reducido entre 40 y $66 \%$, en relación con el movimiento del control. Los extractos metanólicos de ambos desechos fueron también los de mayor actividad. Aunque el extracto metanólico de orujo fue levemente más activo respecto al escobajo.

Es importante resaltar que la cepa hospitalaria fue ligeramente más susceptible al efecto de los extractos ensayados de los desechos del vino blanco, como puede interpretarse de las figuras 4, 5 y 6 comparado con la cepa de referencia P. aeruginosa ATCC 27853. 


\section{Swarming de Pseudomonas aeruginosa LVP65}

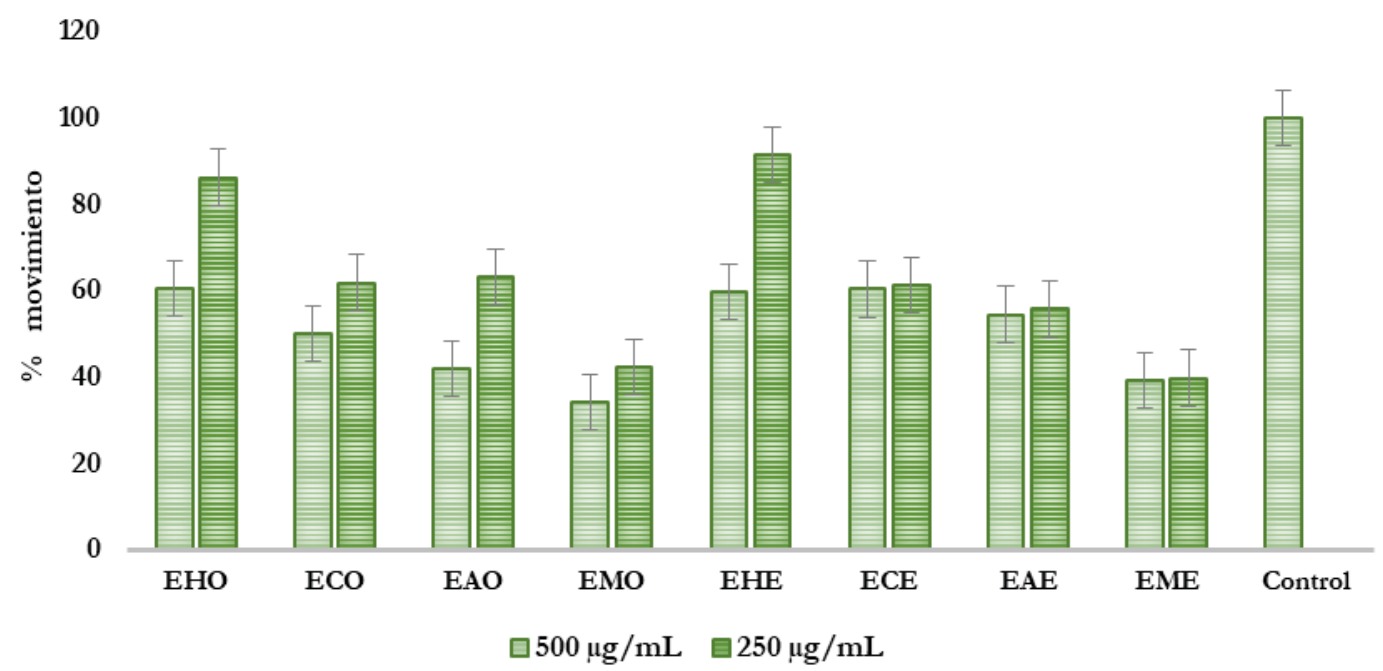

Fig. 4. Promedio de los radios del halo de movimiento swarming de Pseudomonas aeruginosa LVP65 expresados en porcentaje. EHO: extracto hexánico de orujo, ECO: extracto clorofórmico de orujo; EAO: extracto acetato de etilo de orujo; EMO: extracto metanólico de orujo; EHE: extracto hexánico de escobajo; ECE: extracto clorofórmico de escobajo; EAE: extracto acetato de etilo de escobajo; EME: extracto metanólico de escobajo.

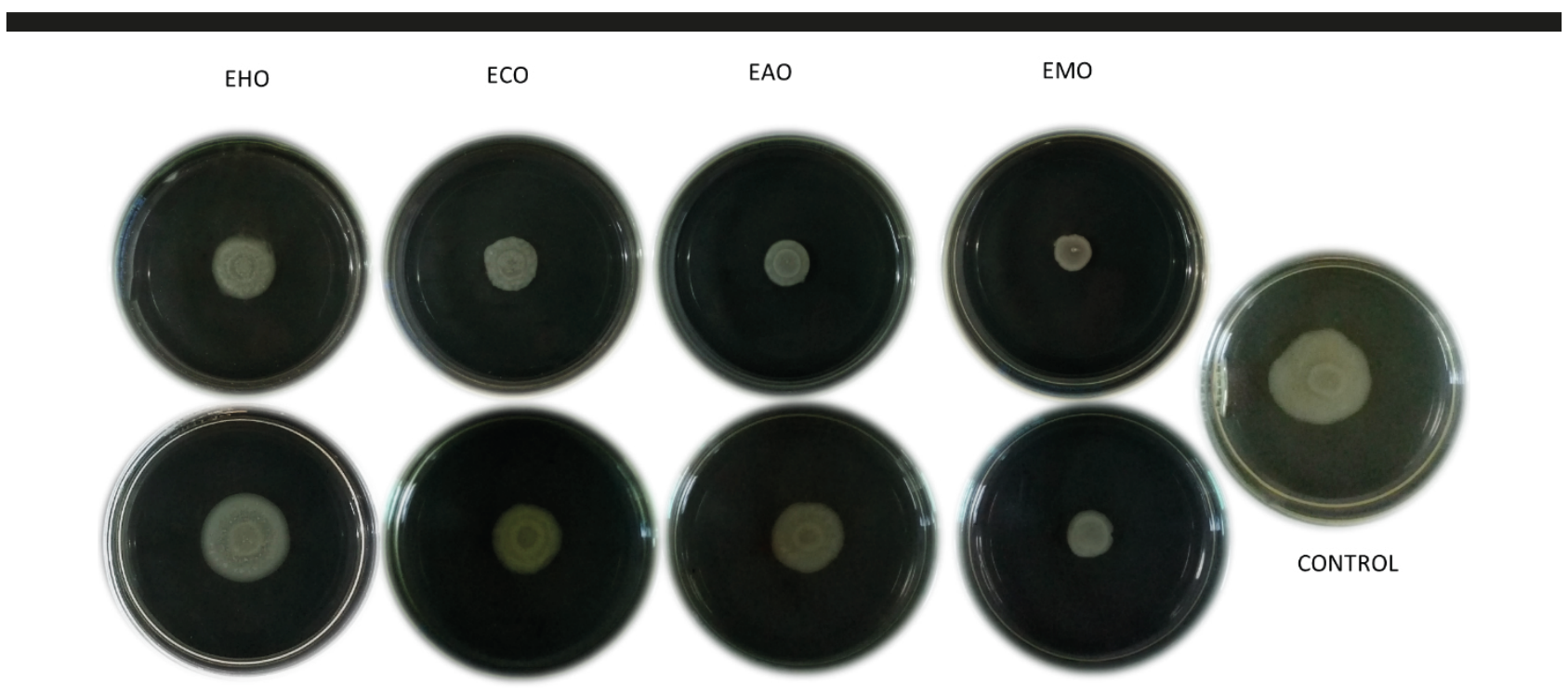

Fig. 5. Motilidad tipo swarming de P. aeruginosa LVP65 en presencia de extractos de escobajo de vino Torrontés a $500 \mu \mathrm{g} / \mathrm{mL}$ (fila superior) y a $250 \mu \mathrm{g} / \mathrm{mL}$ (fila inferior). EHO: extracto hexánico de orujo, ECO: extracto clorofórmico de orujo; EAO: extracto acetato de etilo de orujo; EMO: extracto metanólico de orujo. 


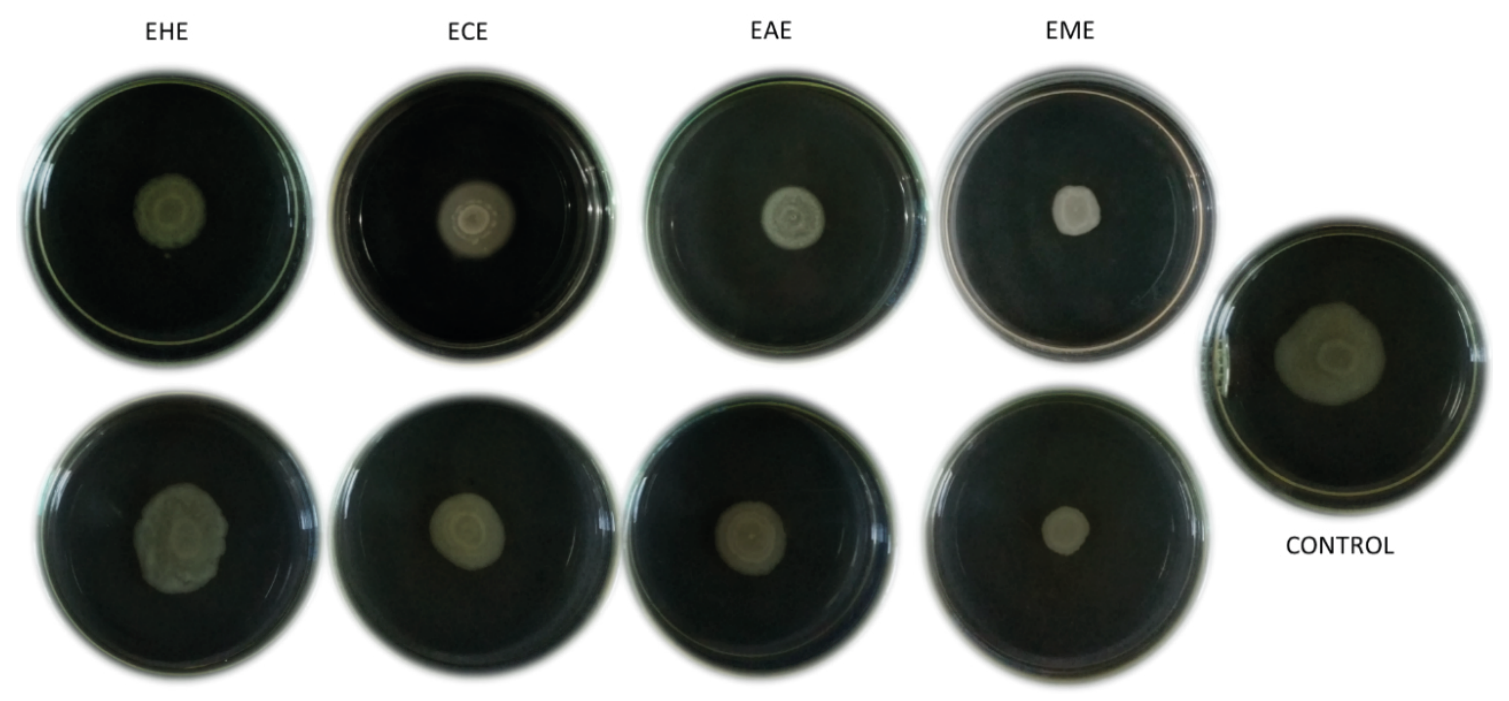

Fig. 6. Motilidad tipo swarming de $P$. aeruginosa LVP65 en presencia de extractos de escobajo de vino Torrontés a $500 \mu \mathrm{g} / \mathrm{mL}$ (fila superior) y a $250 \mu \mathrm{g} / \mathrm{mL}$ (fila inferior). EHE: extracto hexánico de escobajo; ECE: extracto clorofórmico de escobajo; EAE: extracto acetato de etilo de escobajo; EME: extracto metanólico de escobajo.

\section{Swimming de Pseudomonas aeruginosa ATCC 27853}

La motilidad tipo swimming cobra importancia en las etapas tempranas de la formación de biofilm, por lo que es clave evaluar el efecto de los extractos en esta motilidad. Como se observa en las figuras 7 y 8 , la capacidad de los extractos de orujo y escobajo de disminuir el halo de movimiento bacteriano es limitada y alcanza una inhibición máxima del $37 \%$ en el extracto acetato de etilo de escobajo a 500 $\mu \mathrm{g} / \mathrm{mL}$ respecto al control. Los otros extractos afectaron el swimming de la cepa de colección desde un 14 al $30 \%$, en ambas concentraciones. 


\section{$S_{w i m m i n g}$ de Pseudomonas aeruginosa ATCC 27853}

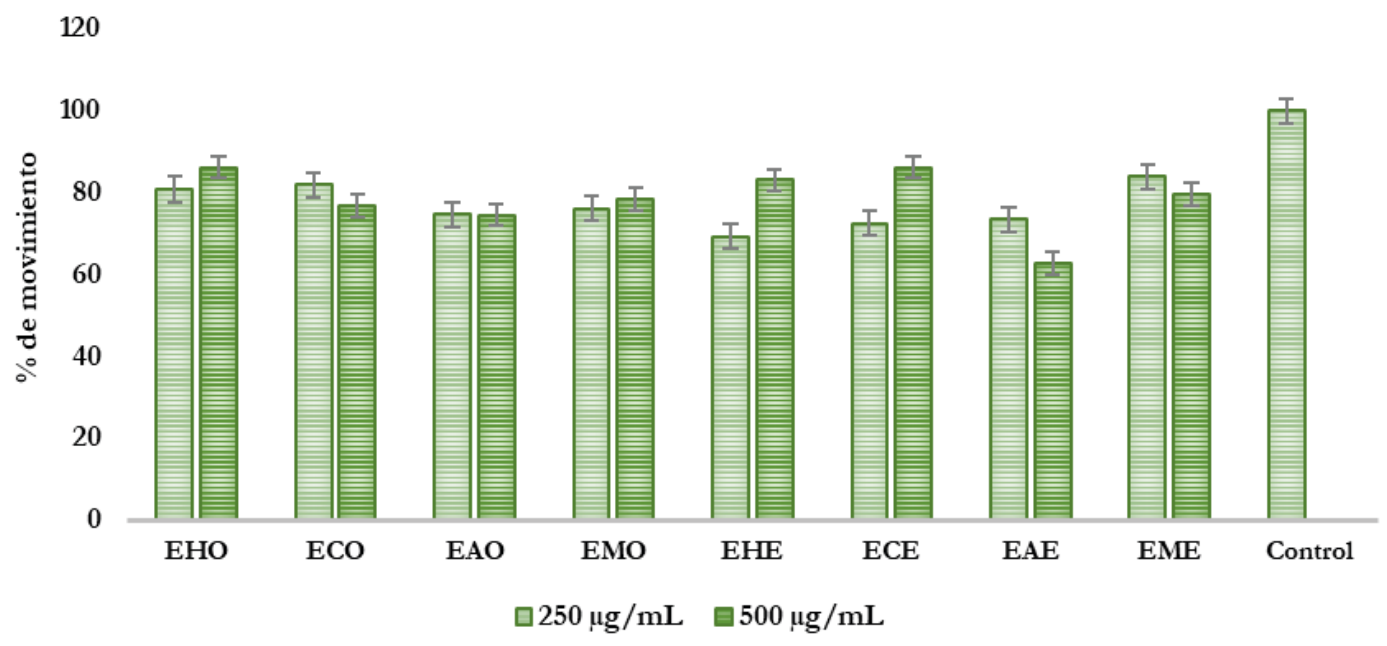

Fig. 7. Promedio de los radios del halo de movimiento swimming de Pseudomonas aeruginosa ATCC 27853 expresados en porcentaje. EHO: extracto hexánico de orujo; ECO: extracto clorofórmico de orujo; EAO: extracto acetato de etilo de orujo; EMO: extracto metanólico de orujo; EHE: extracto hexánico de escobajo; ECE: extracto clorofórmico de escobajo; EAE: extracto acetato de etilo de escobajo; EME: extracto metanólico de escobajo.

\section{Swimming de Pseudomonas aeruginosa LVP65}

La motilidad tipo swimming de la cepa LVP65 fue atenuada en menor grado por los extractos en relación con lo observado en la cepa de colección. El único extracto capaz de disminuir un $30 \%$ la diseminación bacteriana fue el extracto clorofórmico de orujo, ya que los demás extractos no lograron superar el $20 \%$ de inhibición (figura 8). 


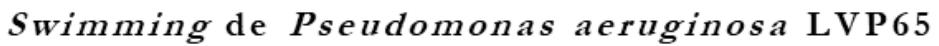

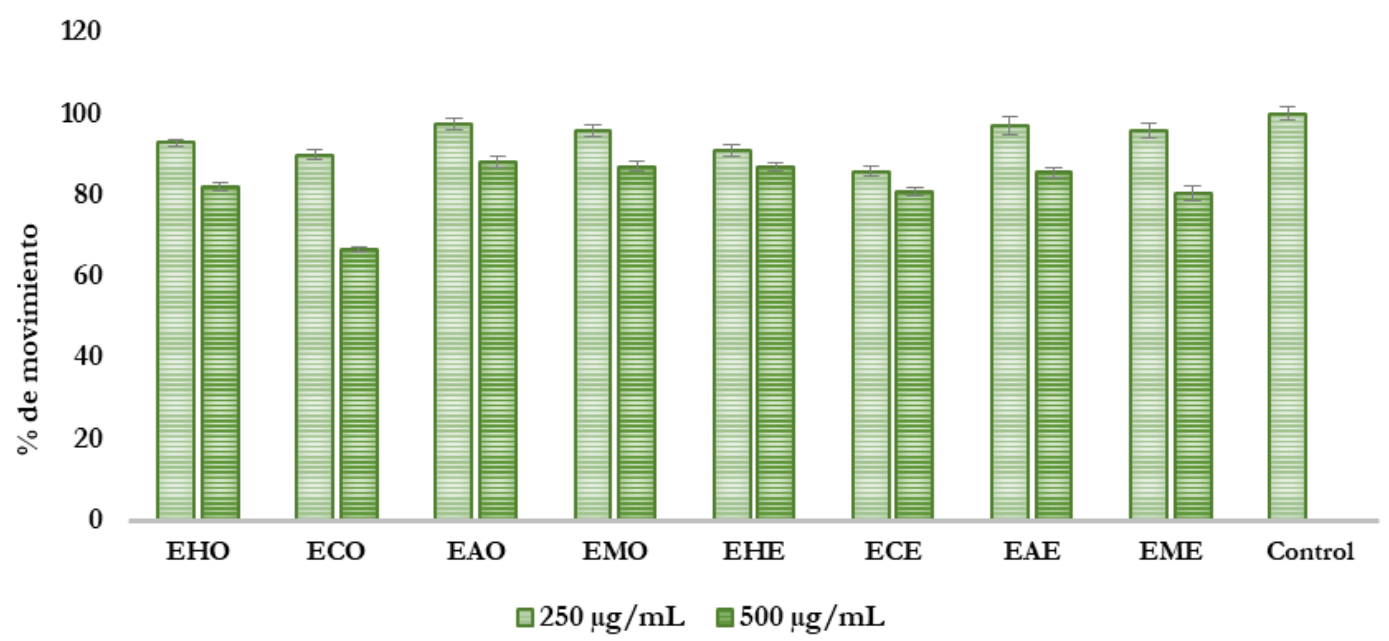

Fig. 8. Promedio de radios del halo de movimiento swimming de Pseudomonas aeruginosa LVP65 expresados en porcentaje. EHO: extracto hexánico de orujo; ECO: extracto clorofórmico de orujo; EAO: extracto acetato de etilo de orujo; EMO: extracto metanólico de orujo; EHE: extracto hexánico de escobajo; ECE: extracto clorofórmico de escobajo; EAE: extracto acetato de etilo de escobajo; EME: extracto metanólico de escobajo.

\section{Efecto de los extractos en el $Q S$ bacteriano}

Se analizó el efecto de los extractos de orujo y escorbajo de vino Torrontés en el $Q S$ bacteriano utilizando las cepas Chromobacterium violaceum ATCC 12472 y C. violaceum CV026. Del total de los ocho extractos ensayados de los desechos de vino Torrontés, tres de ellos mostraron actividad de detección antiquórum en el bioensayo en placa.

El extracto acetato de etilo de orujo de vino Torrontés presentó una prometedora actividad de anti- $Q S$ y se observó una zona de inhibición opaca blanca clara en las placas de la cepa $C$. violaceum ATCC 12472 en dosis de $5 \mathrm{mg}$. Asimismo, los extractos metanólicos en ambos desechos en la dosis más alta exhibieron la presencia de halos de menor tamaño de inhibición del $Q S$ bacteriano, mientras que los extractos acetato de etilo de escobajo mostraron actividad antibacteriana en ambas dosis de ensayo. 


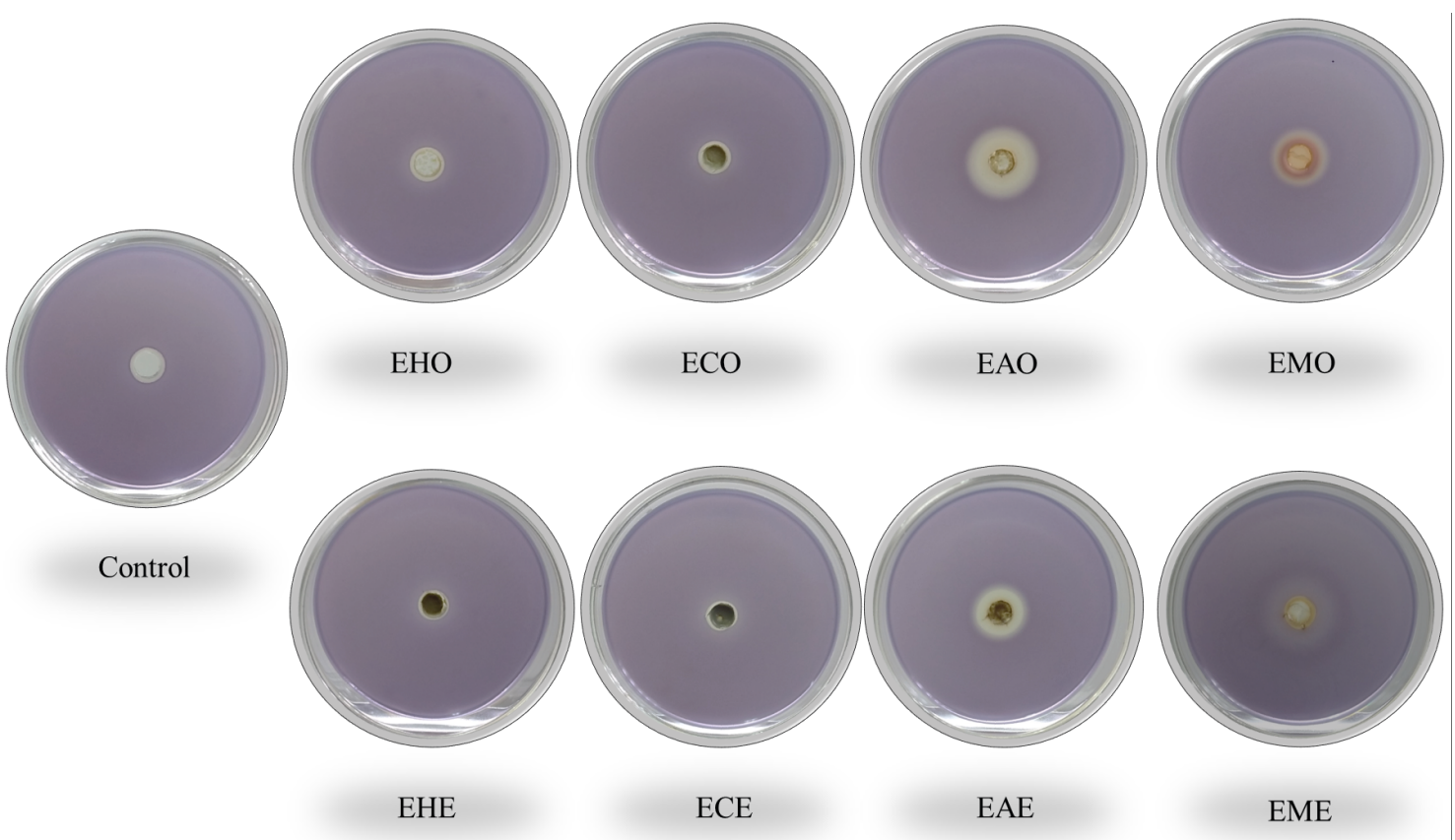

Fig. 9. Ensayo biosensor de $Q S$ con los extractos de orujo y escobajo de vino Torrontés a una concentración de $5 \mathrm{mg}$. EHO: extracto hexánico de orujo; ECO: extracto clorofórmico de orujo; EAO: extracto acetato de etilo de orujo; EMO: extracto metanólico de orujo; EHE: extracto hexánico de escobajo; ECE: extracto clorofórmico de escobajo; EAE: extracto acetato de etilo de escobajo; EME: extracto metanólico de escobajo; Control: C. violaceum ATCC 12472.

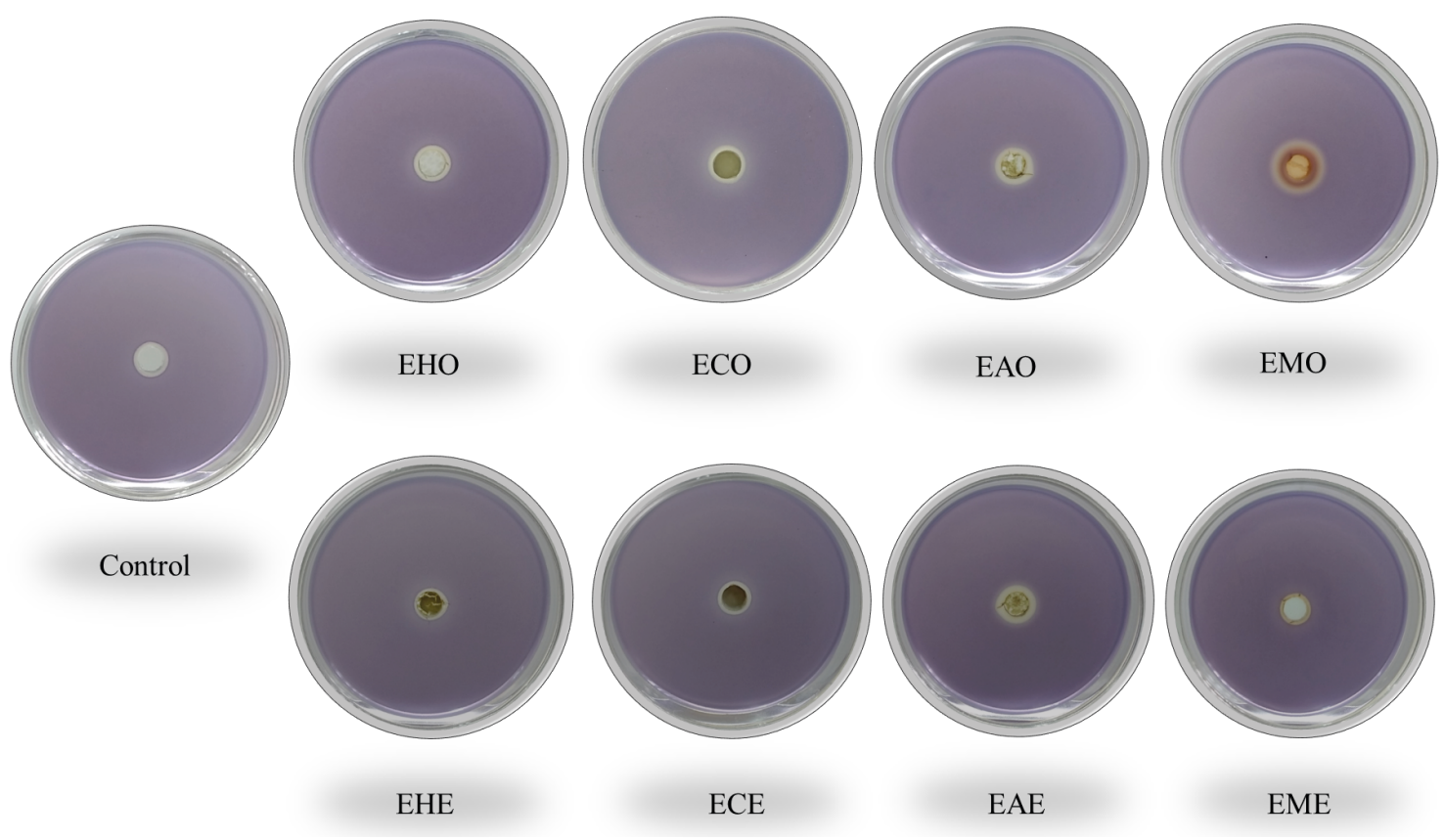


Fig. 10. Ensayo biosensor de $Q S$ con los extractos de orujo y escobajo de vino Torrontés a una concentración de 2,5 mg. EHO: extracto hexánico de orujo; ECO: extracto clorofórmico de orujo; EAO: extracto acetato de etilo de orujo; EMO: extracto metanólico de orujo; EHE: extracto hexánico de escobajo; ECE: extracto clorofórmico de escobajo; EAE: extracto acetato de etilo de escobajo; EME: extracto metanólico de escobajo; Control: Chromobacterium violaceum ATCC 12472.

Los extractos metanólicos a una dosis de $5 \mathrm{mg}$ presentaron actividad anti-QS que se manifestó por la presencia de halos claros con desarrollo de colonias sobre un fondo violeta. Por su parte, los extractos acetato de etilo de ambos residuos fueron activos a las concentraciones ensayadas. Los extractos menos polares (clorofórmico y acetato de etilo) mostraron actividad anti-QS solo a la concentración más alta, como muestran las figuras 11 y 12 .

La actividad observada podría deberse a los compuestos fenólicos que están presentes en las muestras analizadas de acuerdo a datos de bibliografía consultados.
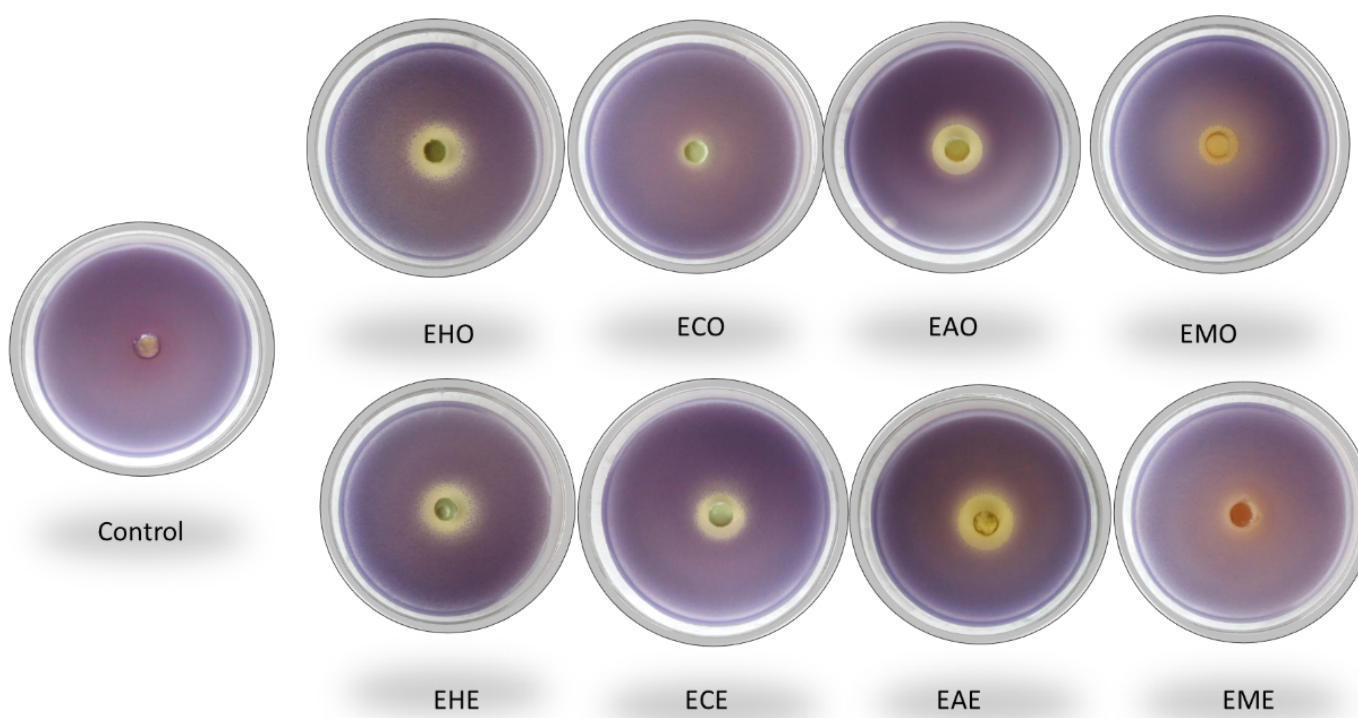

EAO

EMO
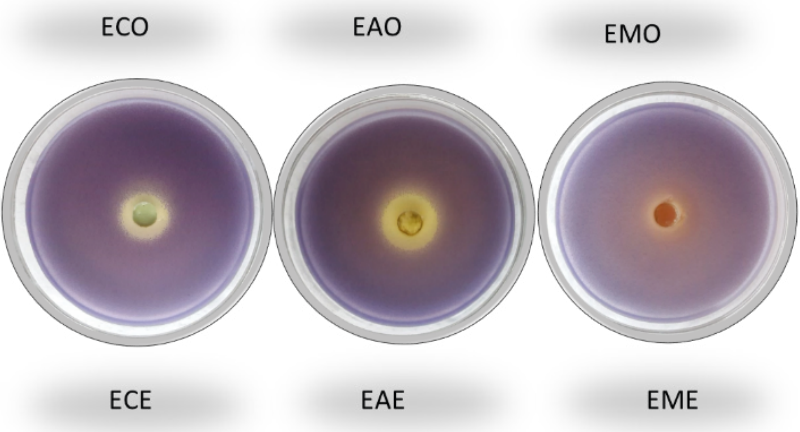

Fig. 11. Ensayo biosensor de $Q S$ con los extractos de orujo y escobajo de vino Torrontés a una concentración de $5 \mathrm{mg} /$ mL. EHO: extracto hexánico de orujo, ECO: extracto clorofórmico de orujo; EAO: extracto acetato de etilo de orujo; EMO: extracto metanólico de orujo; EHE: extracto hexánico de escobajo; ECE: extracto clorofórmico de escobajo, EAE: extracto acetato de etilo de escobajo; EME: extracto metanólico de escobajo; Control: C. violaceum CV026. 


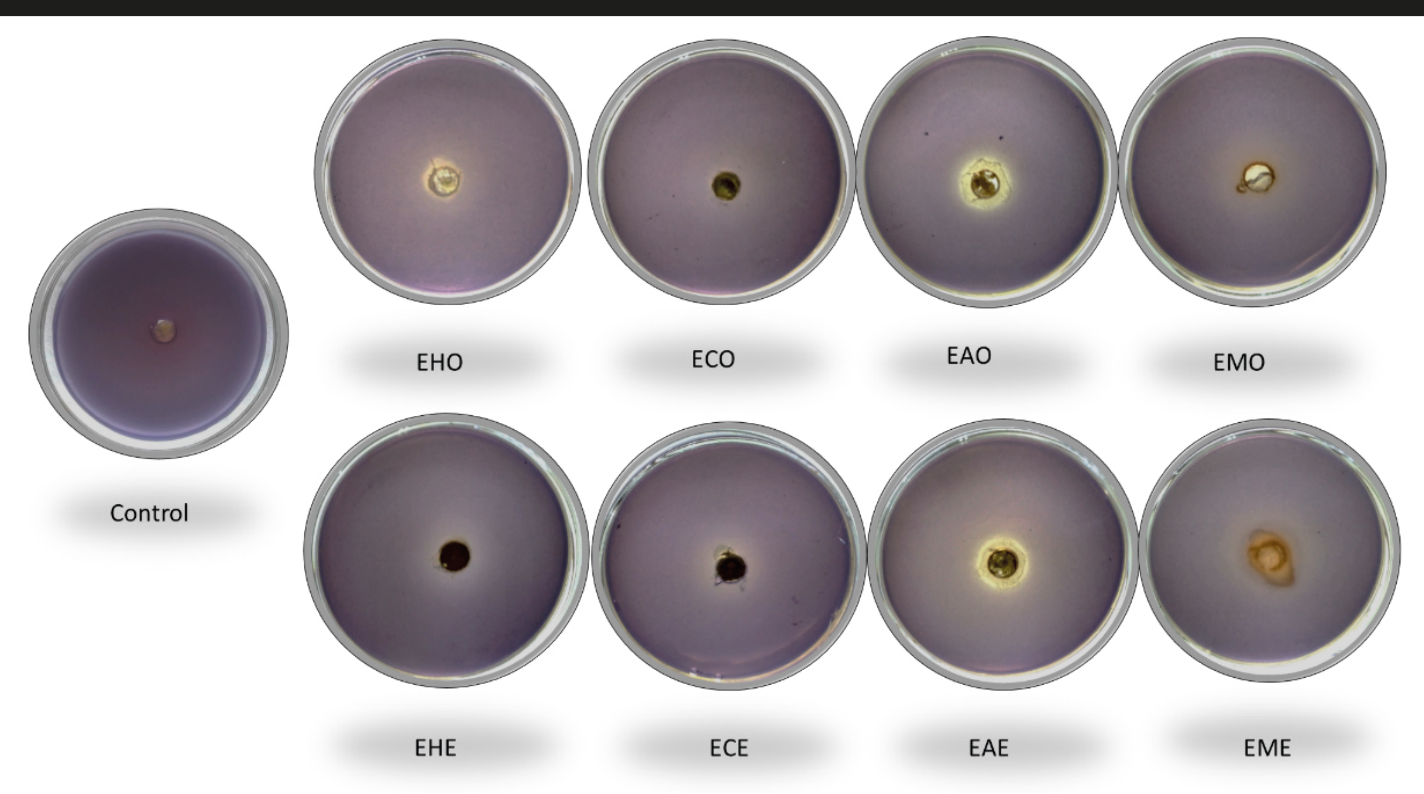

Fig. 12. Ensayo biosensor de $Q S$ con los extractos de orujo y escobajo de vino Torrontés a una concentración de 2,5 mg/ mL. EHO: extracto hexánico de orujo; ECO: extracto clorofórmico de orujo; EAO: extracto acetato de etilo de orujo; EMO: extracto metanólico de orujo; EHE: extracto hexánico de escobajo; ECE: extracto clorofórmico de escobajo; EAE: extracto acetato de etilo de escobajo; EME: extracto metanólico de escobajo; Control: C. violaceum CV026.

\section{DISCUSIÓN}

Actualmente, la investigación de productos naturales cobra un renovado interés en la búsqueda de sustancias con potencial para interrumpir la comunicación bacteriana y el mecanismo por el cual actúan. Se ha determinado que al bloquear el mecanismo de comunicación químico se afecta directamente la patogenicidad y la capacidad del microorganismo para propagarse [19]. Según este fenotipo de pigmentación fácilmente observado, las cepas de $C$. violaceum se pueden usar para detectar diversos aspectos de la actividad QS mediada por AHL [20].

Entre los productos naturales, los subproductos agroalimentarios y, entre ellos, los subproductos de la bodega constituyen una fuente importante de polifenoles que pueden explotarse como ingredientes activos en las industrias farmacéutica y cosmética, o como aditivos en alimentos, lo que contribuye a la sostenibilidad del sistema agroalimentario.

Se han informado propiedades anti-QS de varios extractos de productos naturales. Los estudios realizados en Mangifera indica y C. cyminum informaron un efecto similar en la inhibición del pigmento $[21,22]$. Otros autores investigaron el efecto de residuos industriales de tomate (Lycopersicon esculentum), limón (Citrus limon), zanahoria (Daucus carota) e hinojo (Foeniculum vulgare, variación dulce) para inhibir el QS de $C$. violaceum, empleando dosis del orden de miligramos y unicamente el extracto derivado del limón produjo inhibición a $100 \mu \mathrm{g}$ [23]. 
En este estudio, los extractos metanólicos y acetato de etilo de orujo y escobajo del vino Torrontés se mostraron activos. Los ensayos para determinar la capacidad anti-QS demostraron una disminución significativa en la producción de violaceína para las cepas de $C$. violaceum probadas. El hecho de que inhiban la cepa ATCC sugiere que el efecto puede ser por inhibición en la síntesis del autoinductor o por una inhibición competitiva de la unión del mismo al sitio blanco que desencadena el $Q S$. El mayor efecto observado en la cepa mutante sugiere claramente en los extractos una inhibición competitiva al unirse al sitio activo del autoinductor. Esto podría establecer las muestras como un tratamiento alternativo una vez producida la contaminación bacteriana.

Como se dijo anteriormente, un mecanismo de virulencia, dependiente de $Q S$, es el movimiento de swarming en $P$. aeruginosa, el cual fue disminuido por los extractos polares de orujo y escobajo de vino Torrontés, en un rango del 44 al $67 \%$, mostrándose ligeramente más susceptible la cepa hospitalaria comparada con la cepa de referencia $P$. aeruginosa ATCC para ambas dosis ensayadas (250 $\mu \mathrm{g} / \mathrm{mL}$ y $500 \mu \mathrm{g} / \mathrm{mL})$. Análogamente, los extractos acuosos de Vaccinium angustifolium y Zingiber officinale, ricos en polifenoles, disminuyeron el swarming de P. aeruginosa PAO1 en un 50 y $53 \%$, respectivamente, a una concentración de $10 \mathrm{mg} / \mathrm{mL}$ [20,25]. Mientras que Huasin y colaboradores [21] informaron una disminución de la motilidad swarming P. aeruginosa PAO1 en un $74 \%$ por acción de un extracto metanólico derivado de hojas de Magnifera indica a $800 \mu \mathrm{g} / \mathrm{mL}$.

En este trabajo los extractos de orujo y escobajo de vino blanco disminuyeron notablemente la motilidad bacteriana de $P$. aeruginosa, lo cual coincide con los resultados obtenidos por Niu y colaboradores [25], que mostraron mayor efecto inhibitorio en la motilidad swarming que en el swimming y sugirieron que algunos compuestos presentes en los extractos metanólicos podrían tener la capacidad de suprimir la expresión de genes relacionados con la motilidad swarming. Asimismo, De Marco y colaboradores [26] informaron que los extractos hidroalcohólicos de propóleos y resinas de yemas de álamo fueron capaces de inhibir parcialmente el movimiento swimming de $P$. aeruginosa. La reducción de esta motilidad, mediada por flagelos de $P$. aeruginosa, aumenta la fuerza de repulsión de la cepa con la superficie, inhibiendo una posible adhesión estable con esta, lo cual afecta al progreso hacia la formación de un biofilm maduro, el cual es factor de virulencia dependiente de QS [10].

\section{CONCLUSIONES}

Los desechos del vino pueden reducir notablemente la motilidad swarming y, por lo tanto, disminuyen la capacidad de invasión y diseminación de $P$. aeruginosa. Estos efectos están relacionados con la capacidad de inhibir el $Q S$ bacteriano demostrado en cepas de Chromobacterium violaceum.

Los extractos también disminuyeron la motilidad swimming de las dos cepas de $P$. aeruginosa estudiadas. Si bien este movimiento no está regulado por QS, juega un papel esencial en la primera etapa de formación de biofilm, en la adhesión célula/célula y célula/superficie, por lo que su inhibición dificultaría la formación del biofilm, principal factor de virulencia bacteriano.

El orujo de uva representa una fuente prometedora y factible (de bajo coste y ampliamente disponible) para la extracción y el aislamiento de compuestos bioactivos capaces de intervenir en procesos de virulencia bacterianos. 


\section{AGRADECIMENTOS}

Los autores agradecen el financiamiento a SCAIT-UNT (PIUNT D26/638-1), la Agencia Nacional de Promoción Científica y Técnica, ANPCyT (PICT 02071 u 02514) y al Consejo Nacional de Investigaciones Científicas y Técnicas, CONICET (PIP 662). También a la Bodega Vasija Secreta de Cafayate, en Argentina, por proveer las muestras para el estudio.

\section{REFERENCIAS BIBLIOGRÁFICAS}

[1] Horn N, Bhunia AK. Food-associated stress primes foodborne pathogens for the gastrointestinal phase of infection. Frontiers in Microbiology. 2018;9:1962. Frontiers Media S. A.

[2] Waters CM, Bassler BL. QUORUM SENSING: Cell-to-Cell Communication in Bacteria. Annu Rev Cell Dev Biol. 2005;21(1):319-46.

[3] Eickhoff MJ, Bassler BL. SnapShot: Bacterial Quorum Sensing. Cell. Cell Press. 2018;174:13281328.e1.

[4] Antonioli L, Blandizzi C, Pacher P, Guilliams M, Haskó G. Quorum sensing in the immune system. Nature Reviews Immunology. Nature Publishing Group. 2018;18:537-8.

[5] Juhas M, Eberl L, Tummler B. Quorum sensing: the power of cooperation in the world of Pseudomonas. Environ Microbiol. 2005;7(4):459-71.

[6] Pallaval Veera Bramhachari. Introduction to Quorum sensing Research in Diverse Microbial Systems. En: Implication of Quorum Sensing System in Biofilm Formation and Virulence. Springer Singapore. 2018:3-6.

[7] Shrout JD, Chopp DL, Just CL, Hentzer M, Givskov M, Parsek MR. The impact of quorum sensing and swarming motility on Pseudomonas aeruginosa biofilm formation is nutritionally conditional. Mol Microbiol. 2006;62(5):1264-77.

[8] Ha DG, Kuchma SL, O'Toole GA. Plate-based assay for swarming motility in Pseudomonas aeruginosa. Methods Mol Biol. 2014;1149:67-72.

[9] Ha DG, Kuchma SL, O’Toole GA. Plate-Based assay for swimming motility in pseudomonas aeruginosa. Methods Mol Biol. 2014;1149:59-65.

[10] Ha D, Biofilms GO-M, 2015 undefined. c-di-GMP and its Effects on Biofilm Formation and Dispersion: a Pseudomonas Aeruginosa Review. Microbial Biofilms. 2015:301-317.

[11] Koh C-L, Sam C-K, Yin W-F, Ying Tan L, Krishnan T, Meng Chong Y, et al. Plant-Derived Natural Products as Sources of Anti-Quorum Sensing Compounds. Sensors. 2013:6217-28.

[12] Durán N, Justo GZ, Durán M, Brocchi M, Cordi L, Tasic L, et al. Advances in Chromobacterium violaceum and properties of violacein-Its main secondary metabolite: A review. Biotechnol Adv. 2016;34(5):1030-45.

[13] Teixeira A, Baenas N, Dominguez-Perles R, Barros A, Rosa E, Moreno DA, et al. Natural bioactive compounds from winery by-products as health promoters: a review. Int J Mol Sci [Internet]. 4 de septiembre de 2014;15(9):15638-78.

[14] Christ KL, Burritt RL. Critical environmental concerns in wine production: An integrative review. Journal of Cleaner Production. 2013; 53:232-42. 
[15] Dwyer K, Hosseinian F, Rod M. The Market Potential of Grape Waste Alternatives. J Food Res. 2014;3(2):91.

[16] McClean KH, Winson MK, Fish L, Taylor A, Chhabra SR, Camara M, et al. Quorum sensing and Chromobacterium violaceum: Exploitation of violacein production and inhibition for the detection of N-acylhomoserine lactones. Microbiology. 1997;143(12):3703-11.

[17] Cao H, Lai Y, Bougouffa S, Xu Z, Yan A. Comparative genome and transcriptome analysis reveals distinctive surface characteristics and unique physiological potentials of Pseudomonas aeruginosa ATCC 27853. BMC Genomics. 2017;18(1).

[18] Harshey RM, Matsuyama T. Dimorphic transition in Escherichia coli and Salmonella typhimurium: Surface-induced differentiation into hyperflagellate swarmer cells. Proc Natl Acad Sci U S A. 1994;91(18):8631-5.

[19] Rai N, Rai R, Venkatesh K V. Quorum Sensing vs Quorum Quenching: A Battle with No End in Sight. Kalia VC, editor. New Delhi: Springer India. 2015:173-183.

[20] Chu W, Vattem DA, Maitin V, Barnes MB, McLean RJC. Bioassays of quorum sensing compounds using Agrobacterium tumefaciens and Chromobacterium violaceum. Methods Mol Biol. 2011;692:3-19.

[21] Husain FM, Ahmad I, Al-Thubiani AS, Abulreesh HH, AlHazza IM, Aqil F. Leaf extracts of Mangifera indica L. inhibit quorum sensing - Regulated production of virulence factors and biofilm in test bacteria. Front Microbiol. 2017;8.

[22] Sybiya Vasantha Packiavathy IA, Agilandeswari P, Musthafa KS, Karutha Pandian S, Veera Ravi A. Antibiofilm and quorum sensing inhibitory potential of Cuminum cyminum and its secondary metabolite methyl eugenol against Gram negative bacterial pathogens. Food Res Int. 2012;45(1):85-92.

[23] Di Donato P, Taurisano V, Tommonaro G, Pasquale V, Jiménez JMS, de Pascual-Teresa S, et al. Biological Properties of Polyphenols Extracts from Agro Industry's Wastes. Waste and Biomass Valorization. 2018;9(9):1567-78.

[24] Kordbacheh H, Eftekhar F, pathogenesis SE-M, 2017 undefined. Anti-quorum sensing activity of Pistacia atlantica against Pseudomonas aeruginosa PAO1 and identification of its bioactive compounds. Microbial pathogenesis. 2017;110:390-398.

[25] Niu K, Kuk M, Jung H, Chan K, Kim S. Leaf Extracts of Selected Gardening Trees Can Attenuate Quorum Sensing and Pathogenicity of Pseudomonas aeruginosa PAO1. Indian J Microbiol. 2017;57(3):329-38.

[26] De Marco S, Piccioni M, Pagiotti R, Pietrella D. Antibiofilm and Antioxidant Activity of Propolis and Bud Poplar Resins versus Pseudomonas aeruginosa. Evidence-based Complement Altern Med. 2017;2017. 